Wilfried Floeck

María Francisca Vilches de Frutos (eds.)

Teatro y Sociedad en la España actual

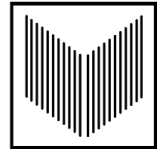


TPT - TEORÍA Y PRÁCTICA DEL TEATRO

INVESTIGACIONES DE LOS SIGNOS CULTURALES

(SEMIÓTICA-EPISTEMOLOGÍA-INTERPRETACIÓN)

TPT - THEORIE UND PRAXIS DES THEATERS

UNTERSUCHUNGEN ZU DEN KULTURELLEN ZEICHEN

(SEMIOTIK-EPISTEMOLOGIE-INTERPRETATION)

TPT - THEORY AND PRACTICE OF THE THEATRE

INVESTIGATIONS ON CULTURAL SIGNS

(SEMIOTICS-EPISTEMOLOGY-INTERPRETATION)

Vol. 13

\section{EDITORES/HERAUSGEBER/EDITORS:}

Alfonso de Toro

Ibero-Amerikanisches Forschungsseminar

Universität Leipzig - D-04107 Leipzig

detoro@rz.uni-leipzig.de

Wilfried Floeck

Institut für Romanistik

Universität Giessen - D-35394 Giessen

Wilfried.Floeck@romanistik.uni-giessen.de

María Francisca Vilches de Frutos

Consejo Superior de Investigaciones Científicas

E-28014 Madrid

vilches@ile.csic.es

José Ramón Alcántara Mejía

Universidad Iberoamericana - México, D. F.

jose.r.alcantara@uia.mx

\section{CONSEJO ASESOR/BEIRAT/PUBLISHING BOARD:}

Erika Fischer-Lichte (Freie Universität Berlin); John P. Gabriele (College of Wooster); Rainer Köppl (Wien); Hans-Thies Lehmann (Universität Frankfurt); Maria Silvina Persino (Trinity College, Hartford); Klaus Pörtl (Universität Mainz); Eli Rozik (University of Tel Aviv); Juan Villegas (University of California, Irvine)

\section{REDACCIÓN:}

René Ceballos (Universität Leipzig, IAFSL) 


\author{
Wilfried Floeck \\ María Francisca Vilches de Frutos (eds.)
}

\title{
Teatro y Sociedad en la España actual
}


Bibliographic information published by Die Deutsche Bibliothek

Die Deutsche Bibliothek lists this publication in the Deutsche Nationalbibliografie; detailed bibliographic data is available on the Internet at http://dnb.ddb.de

La publicación de este volumen ha sido posible gracias a la generosa subvención prestada por el

Ministerio de Educación, Cultura y Deporte

de España, Madrid

(C) Iberoamericana, Madrid 2004

Amor de Dios, 1 - E-28014 Madrid

info@iberoamericanalibros.com

www.ibero-americana.net

(C) Vervuert Verlag, Frankfurt am Main 2004

Wielandstr. 40 - D-60318 Frankfurt am Main

Tel.: +49695974617

Fax: +49695978743

info@iberoamericanalibros.com

www.ibero-americana.net

Reservados todos los derechos

ISBN 84-8489-140-2

ISBN 3-86527-119-7

Depósito legal:

Diseño de la cubierta: Michael Ackermann

Fotocollage de la cubierta: (C) Margret Floeck

Este libro está impreso integramente

en papel ecológico blanqueado sin cloro.

Impreso en Alemania 


\section{ÍNDICE GENERAL}

Agradecimientos

Prólogo

I.- TEATRO Y DEMOCRACIA:

CAMBIOS SOCIOPOLÍTICOS Y GESTIÓN CULTURAL

Creación autorial y gestión teatral:

una interrelación en la escena española contemporánea

$M^{\mathrm{a}}$ Francisca Vilches de Frutos

Teatro y gestión:

el Teatro de La Abadía de Madrid

Antonio B. González

II.- CANON AUTORIAL Y ESCÉNICO:

LO SOCIOPOLÍTICO COMO ELECCIÓN DRAMÁTICA

El tratamiento del machismo en el teatro posfranquista

Dieter Ingenschay 
Luces y sombras de la nueva identidad femenina en el teatro español actual

Pilar Nieva de la Paz.

Personajes políticos y culturales

en el teatro histórico actual:

del Conde-Duque de Olivares a Samaniego

Antonio Fernández Insuela.

Esos laberintos de la conciencia:

Buero Vallejo en la transición y la democracia

Derek Gagen

Alfonso Sastre y Edgar Allan Poe:

una relación literaria

Silvia Monti

Forma y función de un teatro documental español:

"Ahlán", de Jerónimo López Mozo

John P. Gabriele

Lourdes ante Lorca. "El local de Bernardeta A." (1995)

Dru Dougherty

La fauna urbana en el teatro

de José Luis Alonso de Santos: del "moro" a la moralidad

Antonia Amo Sánchez.

Temas sociales conflictivos en el teatro

de José Luis Alonso de Santos

José Rodríguez Richart

"Cachorros de negro mirar", de Paloma Pedrero

y "El traductor de Blumemberg", de Juan Mayorga:

dos acercamientos al neonazismo

Phyllis Zatlin 


\section{III.- LA RENOVACIÓN DE LOS LENGUAJES TEATRALES:}

DISCURSOS TEXTUALES Y ESCÉNICOS

¿Entre posmodernidad y compromiso social?

El teatro español a finales del siglo xx

Wilfried Floeck

Teatralidad y teatrería en la sociedad del espectáculo

(las estrategias del Bufón)

Óscar Cornago Bernal.

¿Fragmentos, elipsis, huecos textuales?

La escritura de los jóvenes autores dramáticos

Susanne Hartwig

El ritmo como paradigma estético

del teatro español actual

Yvette Sánchez

Para una teoría del "no-lugar" en el teatro

español contemporáneo

Anxo Abuín González

Los discursos del cuerpo en la creación

escénica contemporánea

José A. Sánchez

Las servidumbres naturalistas del cine

(sobre algunas adaptaciones cinematográficas

recientes de textos teatrales "problemáticos")

José Antonio Pérez Bowie

"El ajuar de la memoria": un imperativo ético y estético

en "El lápiz del carpintero", de Rivas, Cuña y Reixa

$M^{\mathrm{a}}$ Teresa García-Abad García 
El teatro español de los noventa:

el "humorismo" como clave estética

Isabelle Reck

Entre condenación eterna y salvación:

crítica social y ética en "La marca del fuego" (1986)

y "Leyenda aúrea" (1998), de José María Rodríguez Méndez

Cerstin Bauer-Funke

"Sangre lunar", de José Sanchis Sinisterra:

transgresión de las normas, transgresión de las formas

Monique Martinez Thomas

El texto dramático desde su perspectiva

de puesta en escena

Ernesto Caballero

Innovaciones en escena y diálogo

del teatro español del siglo XX

Klaus Pörtl 


\title{
CREACIÓN AUTORIAL Y GESTIÓN TEATRAL: UNA INTERRELACIÓN EN LA ESCENA ESPAÑOLA CONTEMPORÁNEA
}

\author{
$M^{\mathrm{a}}$ Francisca Vilches de Frutos \\ Consejo Superior de Investigaciones Científicas (Madrid)
}

Iniciado ya el siglo XXI, el debate sobre la crisis y renovación del teatro español sigue abierto, a pesar de que el término crisis lleva utilizándose de manera recurrente desde hace más de cien años. Profesionales e historiadores de este género siguen convocando foros para discutir en torno a la vigencia de un arte que fue mayoritario en la década de los veinte del siglo pasado y que hoy debe ser promovido por las instituciones públicas, salvo en algunas propuestas concretas, caracterizadas bien por la alta calidad de la resolución final de sus puestas en escena, bien por la actualidad de sus temáticas, o bien por su extraordinario despliegue propagandístico, asociado normalmente a figuras muy conocidas del cine y de la televisión.

Cualquier persona que se acerca a los distintos medios de comunicación donde se abordan cuestiones relacionadas con el teatro o participa en encuentros dedicados a analizar los problemas de la escena contemporánea, se encuentra numerosas voces de disconformidad con la marcha del teatro ${ }^{1}$. Pero, conviene preguntarse: ¿por qué sigue prevaleciendo este descontento cuando las cifras de taquilla arrojan en este momento unos dividendos económicos envidiables con aumentos progresivos en la última temporadas de los porcentajes de asistencia del público?

1 Sirvan como muestra tres de los celebrados recientemente: "El teatro español ante el siglo XXI", llevado a cabo, bajo la dirección de César Oliva, en febrero de 2001 en Valladolid y promovido por la Sociedad Estatal España Nuevo Milenio (Primer Acto, 2001, 287: 11); "La producción teatral en España y América”, celebrado en la Casa de América de Madrid, bajo la direccción de Íñigo López de Haro, entre los días 19 y 20 de mayo de 2003, y "Abismo entre Universidad, Crítica y Cartelera", desarrollado en el mismo recinto un mes después, entre el 24 y 25 de junio, bajo la dirección de José Romera Castillo dentro del marco del Seminario Internacional "Teatro, Prensa y Nuevas Tecnologías (1990-2003)”. 
Los datos recogidos en el Anuario de la Sociedad General de Autores y Editores de España muestran la existencia en 2002 de 48.022 representaciones teatrales en España, una cifra superior a la de 2001, cuando se representaron $42.390^{2}$. Durante el pasado año aumentó, además, el número de espectadores, que ha alcanzado los 10,9 millones, lo que implica un incremento de 1,3 millones en relación con el ejercicio anterior. Todo ello ha influido en las cantidades de recaudación, que pasaron de los 80,4 millones de euros en 2001 a los 114, 4 millones en $2003^{3}$. En el caso de Madrid, donde se concentra el 27,7\% del número de espectadores, frente al 17,3\% de Cataluña o al 10,2\% de la Comunidad Valenciana, el número de espectadores ha superado la barrera de los tres millones $(3,04)$, una cifra muy significativa que supera la más alta del período democrático, la correspondiente a la temporada 1984-1985, 2.698.403.

¿Qué razones motivan, pues, este descontento? ¿Podríamos suponer que están influyendo en la delimitación del canon autorial y escénico? Se puede afirmar que en la actualidad continúan sin resolverse algunos de los problemas y reivindicaciones que planteaban los profesionales del medio veinticinco años antes, cuando se produjo una importante transformación en el teatro español, con el fortalecimiento del sector público, que pasó a una posición hegemónica frente al privado, y con la puesta en marcha de una política descentralizadora que permitió una programación continua fuera de los dos grandes núcleos teatrales, Madrid y Barcelona, al crearse centros dramáticos en algunas de las 17 Comunidades Autónomas del país, rehabilitarse las abandonadas salas decimonónicas existentes en muchas pequeñas ciudades, y convocarse numerosos festivales y certámenes ${ }^{4}$. En este momento, como entonces, resulta prioritario regular las relaciones entre el Estado y los profesionales de la escena, de manera que sean integrados sus puntos de vista, se den respuestas a sus expectativas y se arbitren fórmulas para proteger la producción de los llamados autores españoles vivos ${ }^{5}$. Además, se defiende la necesidad de establecer un diálogo fluido con el teatro alternativo, programando de manera progresiva las creaciones de los jóvenes autores en las grandes salas y se aboga por continuar en la búsqueda de nuevos

2 Datos aparecidos en "El Portal de las Artes Escénicas -ARTEZBLAI.COM- Teatro, danza, música, audiovisuales", 27-VI-2003 (http://www.artezblai.com/artezblai/).

3 El 48,9\% del total pertenece a Madrid, en tanto que Cataluña acapara el 24,8\%. Este incremento ha sido mayor que en otras actividades artísticas, como el cine y la música. Véase al respecto R.S. 2003: 57.

4 Puede encontrarse un amplio desarrollo de estas cuestiones en Vilches 1992 y 1996. Véanse también los enfoques de Aznar 1996b y Oliva 2002a, 2002b.

$5 \quad$ Véanse al respecto los ensayos de Vilches 1996; Garrido 1999b; Heras 1999; López Mozo 1997a, 1997b; y Caballero 2001, 2002, 2003. 
lenguajes expresivos a través de un diálogo constante entre creadores textuales y directores escénicos.

Veamos de qué manera han influido estas cuestiones en la creación textual, en los espectáculos que se están programando, y, finalmente, en la conciencia de crisis del sector.

\section{CREACIÓN DRAMÁTICA Y GESTIÓN CULTURAL}

En la actualidad, los profesionales que escriben en los medios de comunicación y participan en los foros donde se debaten cuestiones teatrales están llamando la atención sobre la marginación de los autores españoles vivos tanto de los circuitos de producción pública como de los privados. Retoman así un discurso que había desaparecido de la escena española durante la década de los ochenta, cuando algunos de sus más notables profesionales, formados en colectivos y estéticas alternativas, pasaron a dirigir los centros de producción y gestión teatral de carácter público ${ }^{6}$. Esta integración de directores escénicos en los circuitos de gestión implicó notables transformaciones en su funcionamiento, puesto que llevaron a éstos unos modelos de gestión, unas elecciones temáticas y unos lenguajes teatrales específicos, fruto de su formación y experiencia en el marco dentro del teatro independiente. La promulgación de la Ley de Teatro de 1985, favoreció, además, la recuperación de importantes textos de algunos de los más significativos representantes de la vanguardia histórica - Federico García Lorca, Ramón $\mathrm{M}^{\mathrm{a}}$ del Valle-Inclán, José Bergamín, y Rafael Alberti, entre otrosRecordemos el estreno en 1986, bajo la dirección de Lluís Pasqual, de El público, de García Lorca, aplaudido primero en el Piccolo Teatro di Milano y más adelante en la sede del Centro Dramático Nacional, el Teatro María Guerrero de Madrid, o el impactante estreno en 1988 de La risa en los huesos, un montaje dirigido por Guillermo Heras sobre textos de José Bergamín en la Sala Olimpia, de Madrid, sede del Centro Nacional de Nuevas Tendencias Escénicas. Pero

6 Citemos, entre los más relevantes, a Lluís Pasqual y José Carlos Plaza en el Centro Dramático Nacional; Guillermo Heras en el Centro Nacional de Nuevas Tendencias Escénicas; Hermann Bonninn en el Centre Dramàtic de la Generalitat de Catalunya; Rodolf Sirera y Antoni Tordera en el Centre Dramàtic de la Generalitat Valenciana; Manuel Canseco en el Centro Dramático de Extremadura; Ricardo Iniesta en el Centro Andaluz de Teatro, y José Luis Gómez y Miguel Narros, en el Español de Madrid. 
también permitió la representación de obras censuradas de los autores dramáticos de la Generación Realista y de la Generación Simbolista (Oliva y Vilches 1999).

Los centros dramáticos y salas gestionadas por estos directores acogieron también con un gran despliegue de medios económicos y en la línea de modernización de los lenguajes escénicos propugnada por las vanguardias de los años sesenta (Cornago 1999, 2000), las creaciones de los autores que formaron parte como creadores textuales, directores e intérpretes de los grupos de Teatro Independiente (José Luis Alonso de Santos, Ignacio Amestoy, Benet i Jornet, Fermín Cabal, Jesús Campos, Ángel García Pintado, Rodolf Sirera, Sanchis Sinisterra, Jordi Teixidor, y Alfonso Vallejo, entre otros). Además, en el Centro Nacional de Nuevas Tendencias Escénicas, dirigido por Guillermo Heras, se dieron a conocer obras de jóvenes escritores dramáticos que más adelante han ocupado un relevante puesto en la escena actual (Leopoldo Alas, Alfonso Armada, Sergi Belbel, Ernesto Caballero, Lluïsa Cunillé, Antonio Fernández Lera, Yolanda García Serrano, Rodrigo García, Agustín Iglesias, Ignacio García May, Javier Maqua, Carlos Marqueríe, Ignacio del Moral, Antonio Onetti, Paloma Pedrero, Alfonso Plou, etc.) y se programaron talleres y cursos donde se formaron otros que comienzan a ser conocidos en la actualidad por el gran público (Luis Miguel Climent, José Ramón Fernández, Juan Mayorga, Pedro Manuel Víllora, por ejemplo) (Heras 1999).

Sin embargo, transcurridos unos años, mientras los empresarios privados denunciaban una y otra vez una supuesta competencia desleal del Estado, las cifras arrojadas por las taquillas mostraban un paulatino alejamiento de los espectadores, lo que impulsó a los gestores públicos a revisar sus planteamientos. En Madrid, por ejemplo, después de dos brillantes temporadas, la 1984-85 y la 1985-86 con 2.698 .403 y 2.677.374 espectadores respectivamente, se descendió en la siguiente a 2.214.802. El leve repunte de la temporada 1987-1988 con 2.571.202, no lograría mantenerse en las siguientes: 2.391 .205 (1988-1989); 2.267 .060 (1989-1990); 2.045 .969 (1990-1991); 1.971 .365 (1991-1992); 1.868 .175 (1992-1993); 1.778 .641 (1993-1994); 1.639 .247 (1994-1995); 1.928.142 (1995-1996), у 1.714.751 (1996-1997).

El período comprendido entre 1987 y 1991 muestra con claridad el rumbo de las opciones de los gestores públicos que dejaron fuera de sus programaciones a notables creadores, entre cuyos nombres habría que mencionar a Buero Vallejo, Antonio Gala y Fernando Arrabal (Vilches 1999).

Este discurso crítico sobre la marginación de los autores españoles vivos volvió al teatro español a comienzos de la década de los noventa, cuando el transcurso de los años fue mostrando que no se trataba de una casualidad o moda pasajera. En 1991, entre las conclusiones del I Congreso de Autores Españoles, se 
llegó a plantear la posibilidad de establecer en los teatros públicos un cupo del $50 \%$ de autores españoles vivos. Por primera vez en el período democrático empezaron a cuestionarse los términos de la intervención del Estado en el proceso teatral. Todos parecían coincidir en los mismos puntos. El fortalecimiento del teatro público había supuesto una competencia desleal hacia la iniciativa privada, por lo que la intervención del Estado debía de dirigirse a la creación de "unos centros de producción muy concretos, allí donde no alcance la iniciativa privada", y en ningún caso debía aspirar a "hegemonizar la vida teatral" (Cabal 1993). Las medidas tomadas habían conducido a la marginación de los autores teatrales españoles de las salas teatrales públicas, en especial de los ya consagrados. Además, los modelos de selección de las creaciones elegidas resultaban poco transparentes y no favorecían en muchas ocasiones las mejores propuestas. Por otra parte, la subordinación del teatro a planteamientos políticos podía conducir al escaparatismo, coartaba la libertad de los creadores e hipotecaba el futuro del teatro a un modelo de gestión sometido a los vaivenes electorales, con lo que se podría producir un vacío importante ante la posibilidad de un cambio de sistema que no contemplara la protección del sector público.

Estas críticas, unidas a la necesidad de realizar un ajuste presupuestario debido a la aplicación de los acuerdos de convergencia política y económica con la Unión Europea y al fortalecimiento del proceso de descentralización política, influyeron de nuevo en la evolución de la creación dramática española contemporánea. Comenzaron a adoptarse entonces fórmulas mixtas de gestión y financiación en los teatros públicos: se establecieron convenios con fundaciones (sirvan como ejemplo los firmados con el Teatre Lliure, de Barcelona, o el Teatro de La Abadía, de Madrid); se concedieron espacios públicos a empresas privadas - Teatro de Madrid a Artibus; Teatre Poliorama a TresxTres, Teatro Romea a Anexa/Focus, y cesión del 35\% del Teatre Nacional de Catalunya-; se impulsaron las coproducciones con compañías privadas, y se creó y potenció la Red Nacional de Teatros y Auditorios para la distribución de los espectáculos por las salas teatrales españolas, muchas de las cuales habían sido rehabilitadas gracias al Programa de rehabilitación de teatros de propiedad municipal, subvencionado, sobre todo, por el Ministerio de Obras Públicas y Urbanismo, y promovido desde el Instituto Nacional de las Artes Escénicas y de la Música por el que fuera Director General en aquel entonces, José Manuel Garrido.

Por todo ello, no debe sorprender que desde 1997, con el cambio político que supuso la llegada al poder del Partido Popular en las elecciones legislativas del año anterior, los esfuerzos de los grandes teatros públicos se estén empleando en intentar mostrar a la sociedad española que sus centros acogen las producciones de los autores españoles. ¿Qué mejor prueba de ello que la puesta en 
escena con carácter de estreno o de reposición de un autor que durante años había estado alejado de las salas de titularidad pública, Antonio Buero Vallejo? Desde entonces, se han podido ver de él Las trampas del azar, estrenada en el Centro Cultural de la Villa de Madrid bajo la dirección de Joaquín Vida; La Fundación e Historia de una escalera, repuestas con éxito por el responsable del Centro Dramático Nacional, Juan Carlos Pérez de la Fuente; Misión al pueblo perdido, estrenada por Gustavo Pérez Puig en el Teatro Español, y Madrugada, presentada por Manuel de Blas en el Centre Dramàtic de la Generalitat Valenciana. ¿Qué evidencia más clara de sus intenciones que la programación de algunos textos emblemáticos de la historia del teatro español de la posguerra, bien por su significación en la búsqueda de nuevos lenguajes expresivos $-E l$ cementerio de automóviles, de Fernando Arrabal, y Pelo de tormenta, de Francisco Nieva, presentados en el María Guerrero y el Teatro de La Abadía por el director del Centro Dramático Nacional, Pérez de la Fuente, y Pasodoble, de Miguel Romero Esteo, dirigido por Alfonso Zurro-, bien por su significación ideológica — Las arrecogías del beaterio de Santa María Egipcíaca, de José Martín Recuerda, un espectáculo producido por los Teatres de la Generalitat Valenciana, bajo la dirección de Vicente Genovés-.

Al mismo tiempo y por la misma razón, decidieron poner en escena obras de autores más jóvenes, nacidos mayoritariamente a finales de los cincuenta o ya en la década de los sesenta. Sin embargo, no todos los autores de esta generación se vieron favorecidos por esta línea de actuación. Su elección se vio condicionada, en gran medida, por la continuidad en el proceso de descentralización autonómica. Sin duda uno de los factores más evidentes ha sido su vinculación con aquellas Comunidades Autónomas que han puesto en marcha acciones de protección en los distintos ámbitos de la producción escénica. En el terreno de la creación textual serían los casos de los andaluces Antonio Álamo, Eduardo Calonge, Jorge Márquez, Sara Molina y Antonio Onetti; los valencianos Carles Alberola, Chema Cardeña, Roberto García, Alejandro Jornet, Juan Luis Mira, Francisco Sanguino y Paco Zarzoso; los catalanes y Sergi Belbel, Lluïsa Cunillé, Jordi Galcerán y Jordi Sànchez; los gallegos Xavier Lama y Cándido Pazó; el extremeño Miguel Murillo; el aragonés Alfonso Plou, y el vasco Borja Ortiz de Gondra, por citar algunos de los más relevantes. El desarrollo de modelos de gestión mixta entre centros de titularidad pública propició que estos espectáculos fueran producidos también por otros centros dramáticos y pudieran llegar así durante breves días a los dos grandes núcleos, Madrid y Barcelona. Sirva como ejemplo el montaje de $A$ bocados, un texto de Antonio Álamo, en colaboración con Rafael Gordón y Charo González, que fue producido por el Centro Andaluz de Teatro y el Centro Dramático Nacional. En 
el ámbito de Madrid, sólo los autores con vinculaciones con el medio educativo, concretamente con la Escuela Superior de Arte Dramático, lograron ver estrenadas algunas de sus producciones en los teatros de titularidad pública. Sirva como ejemplo Ernesto Caballero, cuya obra, Destino desierto, fue producida por el Centro Dramático Nacional, al tiempo que se pudo ver en el Teatro de La Abadía ;Santiago de Cuba y cierra España!, en el Centro Cultural de la Villa de Madrid Te quiero... muñeca y en la Sala Galileo, de titularidad municipal, Tierra de por medio. Sin embargo, María Sarmiento y Un busto al cuerpo se llevaron a escena en salas alternativas. Lograron presentar sus obras en los teatros María Guerrero y Pavón ${ }^{7}$, de Madrid, Ignacio García May, Juan Mayorga, Ignacio del Moral, y el más joven, Pedro Manuel Víllora, cuya obra La misma historia ha sido una de las últimas producciones del Centro Dramático Nacional.

Fuera de esta veintena de autores, el resto de los nacidos en la década de los sesenta, muchos de los cuales se alzaron con premios tan prestigiosos como el Marqués de Bradomín, $\mathrm{M}^{\mathrm{a}}$ Teresa León, Rojas Zorrilla y Tirso de Molina ${ }^{8}$, se quedaron fuera de las salas de titularidad pública y tuvieron que estrenar sus creaciones en salas alternativas. Para poder seguir escribiendo, optaron por trabajar en torno a la gestión de salas alternativas y espacios culturales, a la docencia y a la publicación en medios de comunicación - grandes diarios nacionales y revistas especializadas como Primer Acto-. Querría destacar entre éstos a Luis Araújo, Alfonso Armada, José Ramón Fernández, Antonio Fernández Lera, Carlos Marqueríe, Yolanda Pallín, Itziar Pascual y Carlos Sarrió, entre otros.

Con el fin de mantenerse en el complejo sistema de producción teatral, una gran parte de ellos ha optado por aunar las facetas de autor y director de escena de sus propias producciones, por lo que sus creaciones textuales están muy condicionadas por los procesos de puesta en escena. Citemos, como ejemplo, a Angélica Lidell, que ha recabado un gran éxito en las dos últimas temporadas con obras como Hystérica, Once Upon a Time in West Asphixia, El matrimonio Palavrakis, Lesiones incompatibles con la vida y Haemorroísa, o el de Rodrigo García, autor de creaciones como Prometeo, Tempestad, Conocer gente, comer mierda, Protegedme de lo que deseo, Somebody to love, After Sun, La historia de Ronald, el payaso de McDonald's y Compré una pala en Ikea para cavar una tumba, seguidas con entusiasmo por un creciente número de espectadores.

7 Utilizado para la presentación de los montajes de teatro público mientras se han realizado obras de remodelación en el María Guerrero y La Comedia.

8 Sobre la importancia de estos premios en las carreras teatrales de estos escritores, véase Ragué-Arias 1996. 
En estos últimos años, los gestores de los centros dramáticos y salas de titularidad pública no han olvidado el éxito que tuvieron en el período inmediatamente anterior los textos más conocidos de dos de los autores de la vanguardia histórica, Valle-Inclán y García Lorca, cuyas obras han sido repuestas con carácter de estreno una y otra vez. Hay que destacar nuevamente las importantes contribuciones de directores procedentes de Comunidades Autónomas como Cataluña, Galicia y el País Vasco, como Eduardo Alonso, Joan Baixas, Calixto Bieito, Enric Flores, Manuel Guede, Helena Pimienta, y Joan Ollé, entre otros. De Valle-Inclán se han llevado a escena en este último lustro: Luces de bohemia, en dos importantes versiones, la de José Tamayo y la de Helena Pimienta, Retablo de la avaricia, la lujuria y la muerte (dir. José Luis Gómez), El yermo de las almas (dir. Miguel Narros), Farsa y licencia de la reina castiza (dir. Enric Flores), El embrujado (dir. Eduardo Alonso), y Ligazón (dir. Manuel Guede). De García Lorca, se han presentado Yerma (dir. Miguel Narros), Los títeres de Cachiporra (dir. Luis Olmos), La casa de Bernarda Alba (dir. Calixto Bieito), Así que pasen cinco años (dir. Joan Ollé), El paseo de Buster Keaton (dir. Joan Baixas), y Mariana Pineda (dir. Joaquín Vida), entre las más destacadas. Probablemente haya que explicar también por esta causa dos estrenos de gran relevancia: el de San Juan, de Max Aub, en el Principal, de Valencia, una coproducción entre el Centro Dramático Nacional y los Teatres de la Generalitat Valenciana, dirigida por Pérez de la Fuente; y el de Noche de guerra en el Museo del Prado, estrenada en el Teatro de Madrid, bajo la dirección de Ricard Salvat, una producción de la Sociedad Estatal España Nuevo Milenio.

Los teatros públicos tampoco incluyeron en sus producciones propias a los autores que estuvieron vinculados a los grupos de Teatro Independiente. Con la excepción, de nuevo, de figuras circunscritas al ámbito catalán, como Josep Maria Benet i Jornet y Jordi Teixidor; a Galicia, como Roberto Vidal Bolaño y Francisco Taxes, y a Valencia, como Rodolf Sirera, se mantuvo al margen a los autores nacidos en torno a los años cuarenta y principios de los cincuenta, todos ellos en plena productividad, como lo demuestra un repaso a las publicaciones de textos teatrales de los últimos años. Aunque sus temáticas abordan cuestiones de indiscutible actualidad como la guerra de $\operatorname{los} \operatorname{sexos}^{9}$, las consecuencias de la drogadicción, el paro y la marginación, la violencia generada por el tipo de vida urbano, el rechazo social a la emigración, el impacto de las nuevas tecnologías, etc., no lograron convencer a los responsables de los centros públicos, que prefirieron subvencionar, por otra parte, ciclos de lecturas dramatizadas y la publicación de sus textos ${ }^{10}$. Sin embargo, la potenciación de las fórmulas de gestión mixtas para

9 Véase su incidencia en la narrativa y el teatro español en Nieva 2001a, 2001b y 2004.

10 Véase al respecto Checa 2000. 
la producción y distribución de espectáculos en la amplia red de teatros públicos existentes en toda la geografía española sí influyó en el hecho de que algunos promotores privados acometieran el estreno de los textos de varios de estos escritores, los más renombrados, en la seguridad de poder exhibirlos con posterioridad en los teatros pertenecientes a la Red Española de Teatros Públicos o, en el área de la capital, en los dependientes de la Comunidad y el Municipio de Madrid. Dentro de esta amplia nómina habría que mencionar a José Luis Alonso de Santos, Ignacio Amestoy, Jesús Campos, Jesús Cracio, Jerónimo López Mozo, Gerardo Malla, Domingo Miras, Alberto Miralles, y Alfonso Zurro, entre otros.

Por el contrario, sí vieron el potencial de otros autores españoles a la hora de aumentar las cifras de taquilla y demostrar que las gestiones emprendidas habían subsanado la marginación en la que los políticos socialistas habían sumido a los autores españoles. Las programaciones de los grandes teatros públicos se abrieron a conocidos grupos y compañías de teatro independiente, que se han ido transformando en cooperativas privadas para la gestión no sólo de sus propias creaciones, sino también de otros colectivos. Sería el caso de Els Joglars, La Cuadra, La Fura dels Baus, T de Teatre, Dagoll Dagom, Els Comediants, Tricicle, Ur Teatro, Atalaya, y La Zaranda, por ejemplo. Son los que, en la actualidad, están representando, a instancias de los responsables del sector público, al teatro español en ámbitos internacionales como sus paradigmas.

Mientras acaecían estos hechos en el sector público, para lograr atraer espectadores y evitar así la progresiva desertización de las salas teatrales, los espacios privados comenzaron a recurrir a las adaptaciones de éxitos cinematográficos y al reclamo de las figuras televisivas, que empezaron a invadir los escenarios teatrales (Vilches 2001, 2002). Pero no fueron los únicos. También las salas con financiación pública percibieron el potencial del cine y de la televisión como eficaces instrumentos para la incorporación de nuevos públicos. Vieron en ellos un excelente camino para levantar las cifras de taquilla. Recordemos que muchos de los grandes éxitos comerciales de la escena española contemporánea han sido espectáculos basados en thrillers, musicales, y comedias y dramas cuyas temáticas sintonizan con las preocupaciones de la sociedad actual por determinados problemas: las complejas relaciones de la pareja y la negativa incidencia de la violencia y la intolerancia en la sociedad contemporánea. Citemos entre los últimos títulos El príncipe y la corista, de Terence Rattigan; Primera plana, de Billy Wilder y Howard Hawks; Sueños de un seductor, de Woody Allen; 7 novias para 7 hermanos, de Stanley Donen; Cabaret, de Bob Fosse, y El fantasma de la ópera, dirigida sucesivamente por Rupert Julian, Arthur Lubin, Terence Fisher y Dwight H. Little, etc. En ningún caso, los creadores de estas recuperaciones consideran una influencia negativa el recuerdo de la película. Además, a pesar de sus declaraciones, en las que aseguran 
no buscar paralelismos en sus puestas en escena o sus caracterizaciones de los personajes, sino su traducción al lenguaje teatral, lo cierto es que sus montajes están plagados de guiños cinematográficos.

Debemos recordar aquí el notable incremento de las conexiones entre dichas artes en múltiples direcciones. Algunos de los más interesantes autores teatrales del momento han escrito obras cuya fuente de inspiración ha sido el Séptimo Arte: Álvaro del Amo, Beth Escudé, José Ramón Fernández, Ignacio García May, Luis M. González, Raúl Hernández Garrido, Javier Maqua, Juan Mayorga, Borja Ortiz de Gondra, Yolanda Pallín, Itziar Pascual, Sanchis Sinisterra y Francisco Zarzoso, entre otros. Por otra parte, no debemos albergar dudas sobre la presencia de elementos cinematográficos implícitos en muchas de las obras de los autores dramáticos contemporáneos. Cada vez son más numerosos los textos que ofrecen un predominio de la imagen frente a la palabra, la ruptura del discurso narrativo en favor de estructuras fragmentadas en breves escenas, una intensificación de las situaciones en detrimento de los soliloquios o de los largos diálogos entre los personajes, y la esquematización de los caracteres, unos rasgos que los aproximan a los guiones cinematográficos. Paralelamente, directores escénicos como Albert Boadella, Mario Gas, Guillermo Heras, Emilio Hernández, Adolfo Marsillach, Carlos Martín, Juan Carlos Pérez de la Fuente, Mara Recatero, José Carlos Plaza, Tamzin Twonsend, etc. han jugado con las posibilidades escénicas de recursos como la proyección de imágenes sobre una pantalla, los juegos cromáticos en blanco y negro, o el reclamo que supone la presencia de conocidos rostros cinematográficos y televisivos: Juan Echanove, Lucía San Martín, Carlos Sobera, Joel Jordan ${ }^{11}$, Antonio Molero, Ana Duato, Lola Baldrich, etc. Algunos de ellos, incluso, basándose en esta popularidad se han aventurado a montar sus propios espectáculos en salas alternativas ${ }^{12}$.

\section{CONCLUSIONES}

Como consecuencia de todas estas medidas, el descontento se ha instalado en la vida escénica española actual. Frente al aumento de las cifras de asistencia de es-

11 Uno de los últimos espectáculos presentados en el Lliure, de Barcelona, bajo la dirección de Alex Rigola, Glengary Glen Ross, de David Mamet, contó con la presencia de este actor, intérprete de la serie televisiva Periodistas.

12 Sirva como ejemplo la reciente presentación en la sala Ítaca, de Madrid, de Javier Gil Valle (Ana y los 7) en Javivi, de Juan Cavestany y el propio autor. 
pectadores, las reivindicaciones que apuntábamos al comienzo de esta ponencia siguen sin visos de solución. Las obras de los autores nacidos entre los veinte y los treinta llegan a los grandes teatros públicos con carácter de reposición y sólo en escasas ocasiones se producen estrenos de sus textos más recientes. Los autores teatrales nacidos entre los cuarenta y los cincuenta ven pasar su oportunidad de consagrarse definitivamente mediante las producciones de los grandes teatros públicos, y muchos de los autores nacidos en los sesenta comienzan a experimentar cierto cansancio al constatar cómo sus creaciones deben continuar representándose en espacios alternativos o buscar los cauces de las lecturas dramatizadas. Por su parte, los gestores de los teatros públicos han de restringir sus programaciones a unas necesidades de descentralización y a unos presupuestos que sólo les permiten acometer producciones en régimen mixto con otros centros públicos y con empresas privadas, quedándose mermada así su propia capacidad de decisión a la hora de acometer una política independiente.

Por lo expuesto con anterioridad, no es difícil deducir la conciencia de desorientación existente en el teatro español actual. Sin encontrar el equilibrio en las relaciones entre lo privado y lo público, se puede afirmar que en este momento todavía no existe una iniciativa privada progresista que sirva de contrapeso a la política emprendida por los teatros públicos, que han optado por buscar la máxima rentabilidad de sus espectáculos reduciendo el número de sus producciones, aumentando el de sus coproducciones, apostando por los autores consagrados de éxito asegurado, aunque sea con carácter de reposición, recurriendo a conocidas caras del mundo del espectáculo cinematográfico y televisivo, dejando el teatro de los autores más jóvenes para el ámbito de las Comunidades Autónomas, y potenciando las lecturas dramatizadas y la publicación de textos teatrales. De todo ello puede colegirse que nos hallamos ante una escena en la que la gestión teatral está condicionando el canon autorial y escénico. 


\section{OBRAS CITADAS}

* Deseo expresar mi agradecimiento a José Ibáñez Haro como ayudante de investigación.

Anderson, Farris (ed.). (1992). The Theatre in Spain in the Twentieth Century. Boulder: Anales de la Literatura Española Contemporánea/Annals of Contemporary Spanish Literature, 17.1-3.

Aznar, Manuel (ed.). (1996a). Veinte años de teatro y democracia en España (1975-1995). Barcelona: Associació d'Idées/Cía. Investigadora de Teatro Español Contemporáneo.

Aznar, Manuel. (1996b). "Teatro español y sociedad democrática (1975-1995)”, en: Aznar, Manuel (1996a), pp. 9-16.

Cabal, Fermín. (1993). Los males del Teatro Nacional, en: ABC (14-V), s. p.

Caballero de las Heras, Ernesto. (2001). "Un bochornoso hecho diferencial". La Razón (18-XII), p. 36.

Caballero de las Heras, Ernesto. (2002). "Los autores somos unos mantas". La Razón (20-I), p. 58.

Caballero de las Heras, Ernesto. (2003). “¿Palabra de autor?”. La Razón (10-VI), p. 50.

Cornago, Óscar. (1999). La vanguardia teatral en España (1965-1975). Del ritual al juego. Madrid: Visor.

Cornago, Óscar. (2000). Discurso teórico y puesta en escena en los años sesenta: la encrucijada de los "Realismos". Madrid: CSIC.

Checa Puerta, Julio. (2000). "1998-1999: últimas ediciones de textos teatrales españoles en lengua castellana", en: Anales de la Literatura Española Contemporánea I Annals of Contemporary Spanish Literature, 25.3, pp. 673-697.

Floeck, Wilfried y Vilches de Frutos, $\mathrm{M}^{\mathrm{a}}$ Francisca. (2004). Teatro y Sociedad en la España actual. Frankfurt am Main: Vervuert.

Garrido, José Manuel. (ed.). (1999a). El Teatro. Murcia: Caja Murcia.

Garrido, José Manuel. (1999b). "Políticas teatrales 1982-1992”, en: Garrido, José Manuel (1999a), pp. 51-57.

Halsey, Martha T. y Zatlin, Phyllis (eds.). (1999). Entre actos: Diálogos sobre Teatro Español entre siglos. University Park: Estreno.

Heras, Guillermo. (1999). “Gestión y creación”, en: Garrido, José Manuel (1999a), pp. 93-100. 
López Mozo, Jerónimo. (1997a). "Un reto para los autores de teatro", en: $A B C$ (30-VIII), p. 30.

López Mozo, Jerónimo. (1997b). "Los autores españoles y el teatro de importación", en: $A B C(17-\mathrm{X})$, p. 42.

Nieva de la Paz, Pilar. (2001a). "La escenificación de los roles sexuales y la censura de género durante el franquismo: el caso de Julia Maura", en: Iberoamericana, 1.2, pp.165-178.

Nieva de la Paz, Pilar. (2001b). "Hacia la construcción del imaginario femenino en las novelas de mujeres durante la Transición política", en: Hispanistica XX, 19, pp. 419-431.

Nieva de la Paz, Pilar. (2004). "Luces y sombras de la nueva identidad femenina en el teatro español actual", en: Floeck, Wilfried y Vilches de Frutos, $\mathbf{M}^{\mathrm{a}}$ Francisca (2004e), pp. 65-86.

Oliva, César. (2002a). Teatro español del siglo XX. Madrid: Síntesis.

Oliva, César. (ed.). (2002b). El teatro español ante el siglo XXI. Madrid: Sociedad Estatal España Nuevo Milenio.

Oliva, César y Vilches de Frutos, M ${ }^{a}$ Francisca. (1999). "El teatro", en: Sanz Villanueva, Santos (1999), pp. 559-678.

R. S. (2003). "El teatro es la actividad artística que más crece en 2002", en: La Razón (26-VI), p. 57.

Ragué i Arias, M José. (1996). El teatro de fin de milenio en España (de 1975 hasta hoy). Barcelona: Ariel.

Romera Castillo, José (ed.). (2002). Del teatro al cine y la televisión en la segunda mitad del siglo XX. Madrid: Visor.

Sanz Villanueva, Santos (ed.). Época Contemporánea: 1939-1975. Primer Suplemento, en: Rico, Francisco (ed.). Historia y crítica de la literatura española. Barcelona: Crítica.

Vilches de Frutos, $M^{\mathrm{a}}$ Francisca. (1992). "Tendencias predominantes de la escena española en la década de los ochenta", en Anderson, Farris (1992), pp. 207-220.

Vilches de Frutos, $M^{\mathrm{a}}$ Francisca (1996). "Teatro público/teatro privado: un debate abierto en el teatro español contemporáneo", en Vilches de Frutos, $\mathrm{M}^{\mathrm{a}}$ Francisca y Dougherty, Dru (1996), pp. 369-387.

Vilches de Frutos, M ${ }^{a}$ Francisca. (1999). "La Generación Simbolista en el Teatro Español Contemporáneo", en: Halsey, Martha T. y Zatlin, Phyllis (1999), pp. 127-136.

Vilches de Frutos, $\mathrm{M}^{\mathrm{a}}$ Francisca (coord. y ed.). (2001-2002). Teatro y cine: la búsqueda de nuevos lenguajes expresivos, 2 vols. Boulder: Anales de la Literatura Española Contemporánea/Annals of Contemporary Spanish Literature, 26.1, 27.1. 
Vilches de Frutos, M ${ }^{a}$ Francisca. (2001). "La captación de nuevos públicos en la escena contemporánea a través del cine", en Vilches de Frutos, $M^{a}$ Francisca (2001-2002), pp. 383-401.

Vilches de Frutos, $M^{a}$ Francisca. (2002). "Teatro, cine y televisión: la captación de nuevos públicos en la escena española contemporánea", en: Romera Castillo, José (2002), pp. 205-221.

Vilches de Frutos, Ma Francisca y Dougherty, Dru (coords. y eds.). (1996). Teatro, Sociedad y Política en la España del Siglo XX. Madrid: Boletín de la Fundación Federico García Lorca, 19-20. 